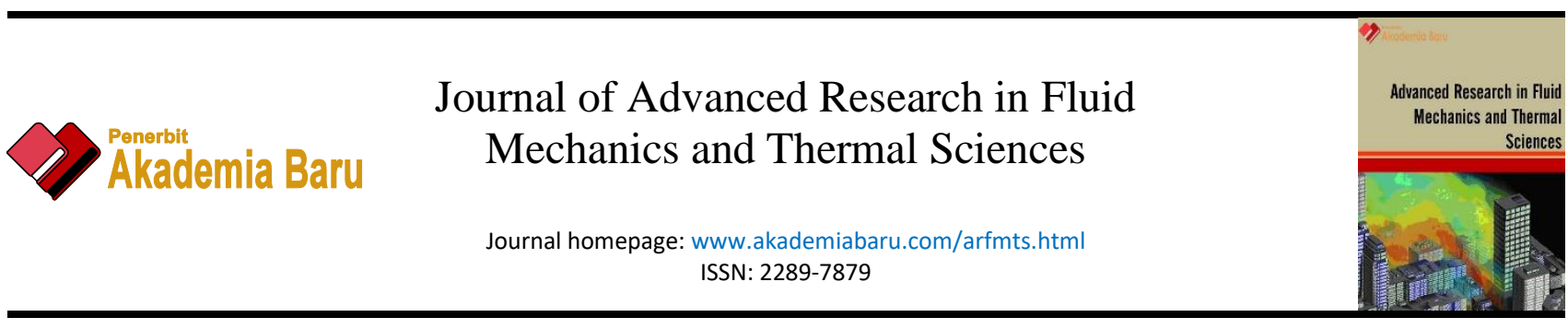

\title{
Newly Developed Thermal Load Profile for Enhancement in Hot Water System
}

\author{
Munirah Nawi ${ }^{1,2}$, Norazlianie Sazali ${ }^{1, *}$, Saiful Anwar Che Ghani ${ }^{1, *}$, Maurice Kettner ${ }^{2}$ \\ Faculty of Mechanical \& Automotive Engineering Technology, Universiti Malaysia Pahang, 26600 Pekan, Pahang, Malaysia \\ Hochschule Karlsruhe-Technik und Wirtschaft, Karlsruhe University of Applied Sciences, 76012 Karlsruhe, Germany
}

\section{ABSTRACT}

\section{Article history:}

Received 28 August 2020

Received in revised form 28 November 2020

Accepted 29 November 2020

Available online 15 January 2021

Keywords:

Hot water system; Hydraulic piping;

Energy saving; Controller system

\begin{abstract}
In recent years with the advancement of technologies, the demand of a reliable and flexible hot water system has increased tremendously. A reliable system includes several critical points which are the degree of safety that a system can offer, the conservation of the energy used and the issue of cost saving. While a flexible system must provide the flexibility in the control of the output from a system desired by the consumers itself. This paper reported on newly developed system for hot water that will greatly benefit consumer. It focuses on building an extension of the cyber physical system in the existing system with purposes of implementing a thermal load profile for consumer who use the hot water system in their daily life. The implementation of the thermal load profile to the system is significant especially in conserving the energy used in the system simultaneously saving any related cost to operate the system. Based on the implemented thermal load profile, the system works in maintaining an output of thermal energy from the hot water supplied to the consumer at a certain value. In addition, it also allows flexibility in controlling the desired temperature by consumers. This new system is simulated in a test bench in the form of laboratory setup. The system uses a control loop feedback mechanism, which means that it will continuously regulate the temperature and mass flow rate of the flowed water in the pipeline for the consumer hot water simulation based on the calculated difference of the actual supplied values and the set values. With the use of standard devices and actuators to drive the system, a robust system can be realized.
\end{abstract}

Copyright $@ 2021$ PENERBIT AKADEMIA BARU - All rights reserved

\section{Introduction}

The idea of resources conservation, climate protection and cost savings are significant for our world today. Therefore, it is very crucial to have an effective solution for all these critical points in order for humankind to live harmoniously together with the environmental ecosystem. In this

\footnotetext{
* Corresponding author.

E-mail address: azlianie@ump.edu.my

* Corresponding author.

E-mail address: anwarcg@ump.edu.my
}

https://doi.org/10.37934/arfmts.79.2.8394 
regard, a thoroughly constructed and planned energy management project nNet is established. This project aims to develop an efficient management system, which enables monitoring and controlling of the energy systems. Most researchers currently opted to use solar for their water heating system $[1,2]$. For this project, a test bench in a laboratory setup is built and assembled for conduction of in-depth research. Laboratory devices such as a Dachs G5.5 combined heat and power unit from SenerTec, a heat storage and a BMW i3 electric vehicle are equipped to facilitate the project.

In continuing this management project successfully, one of sub-project, which targets the consumer, is introduced with a focus on building an extension of the cyber physical system in the system that already exists. The main purpose of this sub-project is to implement a thermal load profile for consumer who use the hot water system in their daily life. This profile contains data for the demand of heat energy from the consumer. With the implementation of this profile, supply of heat energy can be systematically and accurately controlled and monitored without any wastage of energy $[3,4]$. This can be achieved, as the supply of heat energy is limited only to the value, which is demanded by the consumer. Concerning these matters, a laboratory simulation, which simulate the hot water system for consumer, is set up, tested, and validated. The system introduces the implementation of reference value reading from an excel file. Then, the system controlling will accordingly executed based on these values. Raspberry $\mathrm{Pi}$, the controller of this system executes the controlling function in operating the system together with data acquisition function that will update real time data from the running system. Additionally, hydraulic piping construction also plays an important role in this system, where it equips the system with mechanical setup for system test and run. This system will be integrated inside the existing cyber physical energy system when it is fully established and verified.

Concerning these matters, a laboratory simulation, which simulates the hot water system for consumers, is set up, tested, and validated. The system introduces the implementation of reference value (thermal load profile) reading from an excel file. Then, the system controlling will be executed accordingly based on these values. Raspberry pi, the controller of this system executes the controlling function in operating the system together with data acquisition function that will update real time data from the running system. Additionally, hydraulic piping construction also plays an important role in this system, where it equips the system with mechanical setup for system test and run. This system will be integrated inside the existing cyber physical energy system when it is fully established and verified.

There are always challenges in developing a new system, and this also includes this system. It is very crucial for them to be critically and wisely solved in order to get a successful running system. The challenges include engineering the hydraulic piping construction for different water temperature mixing and water mass flow rate regulation. The new extension piping lines need to be in correlation with the existing system without disturbing any other project and successfully performing the desired task of the system. It also at the same time requires a fitted hydraulic piping plan, which promises a smooth hot water flow, which corresponds to the building mechanism, functions, and follows the standard piping construction act. Alongside the mechanical setup, an embedded software system is equipped in this system. It enables the system to be controlled by computer-based algorithms. As for this system, it operates with Raspberry Pi (controller) and Python 3 (control language). There is other study that used SIMPLEC algorithm to design the heat transfer system [5].

Besides, this system requires engineering on how to effectively control energy flow distributed to the consumer and regulate water mass flow rate in the hydraulic pipeline. Essentially, the control system that is managed by Raspberry $\mathrm{Pi}$, needs to synchronize with the rest of the existing Energy Management System, which includes the EtaNet as network and all other cyber physical systems. 
Accuracy of the system in driving the load profile is also a significant point for the system to simultaneously run without so many delay and efficiency issues.

For this system, some engineering ideas and plans in solving all the challenges stated in paragraph above are comprehensively executed. For instance, the use of standard heater and hot water system equipment. Standard equipment is necessary to aid maintenance or any development project later in the future, which also improves compatibility and interoperability between equipment and devices in the whole energy management system. In solving the inaccurate control system by the controller, some specific classes and modules or libraries of Python that are applicable to this new system's need are used. These will complement the new system to an optimized level and reduce software development cost and time. In addition, with Raspberry Pi that used Python is a bonus point to this new system. Python is an interpreted programming language and supported by many operating systems. Importantly, it suited our laboratory requirements, which demand flexibility throughout the whole system. It is relevant not just to our laboratory use but also for future use of the outside world.

Overall, this new system also needs to be verified and validated. The approach of verification and validation of the system was based on a specified thermal load profile. The temperatures and volumetric feet that the developed system sets, and controls were recorded and compared. It has been shown that the system delivers the desired operating values down to accuracy of $+/-1^{\circ} \mathrm{C}$ for temperature value and +/- $0.3 \mathrm{~kW}$ for thermal power value. In addition, a connection to the energy manager could be established to send and receive data.

\subsection{Existing System and Current Hydraulic Piping Plan}

Subsequent to this project is based and connected from the main project, summary on working mechanism, some main equipment and components used in existing laboratory system will briefly explained.

Hydraulic piping plan of the existing system consist of two different water circuit loops that will load up the storage tank with heat energy. First, a circuit loop that consist of heat and power unit as its main component. In this first circuit loop, the CHP unit will process natural gas that it consumed and generate it to electrical power and thermal power. The electrical power will be fed directly into the grid while the thermal power will be discharged via the first water circuit and load the storage tank. Then, the second water circuit loop used condenser for it to operate. The condenser will use the resulting exhaust gas from the CHP unit. This gas will condense and give its portion of heat to the second water loop. This will then supply the heat storage with heat energy. Pump located in the existing system provides required volume flow in the second water circuit while three-way valve controls the flow temperature of the condenser. In addition, heat meters are equipped to the system to measure the temperature of water in the respective loops. Figure 1 shows hydraulic piping plan for the existing laboratory system.

Dachs G5.5 by SenerTec is used in the existing energy system as the CHP unit [6]. It uses the concept of energy efficient technology, which is called cogeneration where it consumes chemical energy of the fuel and then generates electricity and heat at the same time with the use of combustion engine and generator. It is equipped with integrated microprocessor control, which will secure a consistent electrical and thermal output and control unit. In addition, it uses water-cooled asynchronous generator, single-stage gear, and a single-cylinder 4-stroke special engine with a displacement of $580 \mathrm{~cm}^{3}$ that can be operated up to 80000 hours. Electrical power generation is $5.5 \mathrm{~kW}$ and thermal output up to $14 \mathrm{~kW}$. Besides, this unit's exhaust gas temperature can be further utilized with the use of additional condenser. This will then positively affect the used fuel 
efficiency even more. The conversion efficiency into electricity is in range of 24 and 27 percent while conversion efficiency into thermal is between 65 and 72 percent. These will produce an overall efficiency in the range of 89 and 99 percent.

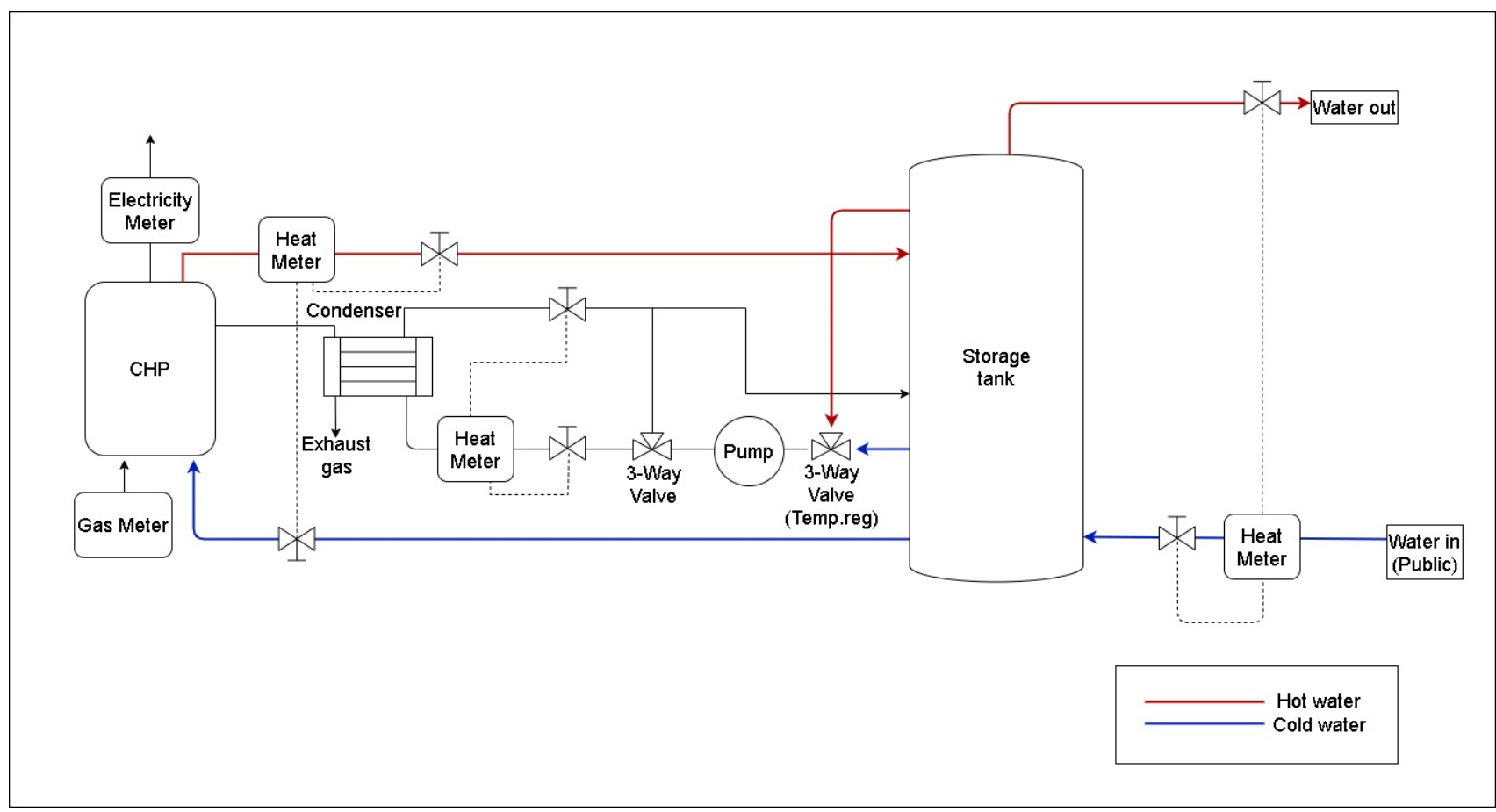

Fig. 1. Existing Hydraulic Piping Plan

The storage tank stores an amount of heat in the form of tap water and compensates the differences between generated and consumed heat output. It is also used as a heat exchanger between the hot water from the heat and power unit and the tap water. The storage tank used in the existing energy system is PL1000/2s by Buderus. It is a combined storage tank with patented thermosiphon technology for drinking water and heating support. It has a storage capacity of $940 \mathrm{~L}$, continuous output of $28 \mathrm{~kW}$ at $688 \mathrm{l} / \mathrm{h}$ and thermal insulation through CFC-free heat protection that allows a power loss of $139 \mathrm{~W}$ [7]. It is also equipped with corrosion protection of hot water tank with Duoclean thermal glaze and magnesium anode. A $100 \mathrm{~mm}$ CFC-free foam with a PE outer skin as the applied thermal protection. The accumulator is loaded from top to bottom and hot water also drawn from above.

The existing energy management system uses a Wireless Local Area Network (WLAN) named as EtaNet. This network is used for energy management system to facilitate and enhance communication between all the sub-systems and machine to machine. It connects the system with Raspberry $\mathrm{Pi}$, which allows the Raspberry $\mathrm{Pi}$ to simultaneously execute control programs and acquiring data from other equipment or devices within the network. It uses protocol type of WLAN where it rules and encoding specification for sending data together with client and server architecture. The use of this network enables the whole system to transmit and receive data at a very fast rate. With this network, a centralized energy management system can be achieved and connection to local database can be established for data storage purpose. 


\section{Literature Review}

This chapter will focus on the literature review mainly on the topic of the hot water system.

\subsection{Hot Water System}

Hot water supply for space heating and domestic use such as for personal hygiene and cleaning task purposes is a continuous demand for daily basis of life. According to consideration of for hot water plumbing by Bhatia [8], heating water is typically the second largest use of energy in residential and commercial buildings (after space heating and cooling).

In that account, a reliable and systematic system is a high-priority need. There are several pivot points as requirements that should be met for this kind of system. For example, the distributed water must be free from any hygienic issues and safe not just to humankind but also to the environment. One of the issues is the hot water system often associated with legionella pneumophila; a type of bacteria that causes Legionnaires' disease. It is a form of atypical pneumonia, which includes symptoms such as cough, shortness of breath, high fever, muscle pains and headache [9]. For immunosuppressed people and those with chronic respiratory conditions, the disease can be fatal [10].

Additionally, temperature is another main point for this system [11]. A desired temperature control is indispensable to accommodate all human needs and essential. The temperature in the distribution pipeline must be store and operate at a temperature of $60{ }^{\circ} \mathrm{C}$ to prevent active breeding of legionella pneumophila bacteria. Legionella bacteria are killed by water temperatures above $50^{\circ} \mathrm{C}$. The higher the temperature the quicker the kill rate. At $60^{\circ} \mathrm{C}$ a time of $2 \mathrm{~min}$ is required to kill 90 percent of the bacteria (Figure 2) [12], so this temperature is recommended for hot water storage -particularly in hospitals and other health-care premises [10]. It also suggested not exceeding the temperature of $60{ }^{\circ} \mathrm{C}$ as this might harm the system with the exposure to corrosion and risk of calcination. The rate of corrosion to occur in hot water is higher than in cold water.

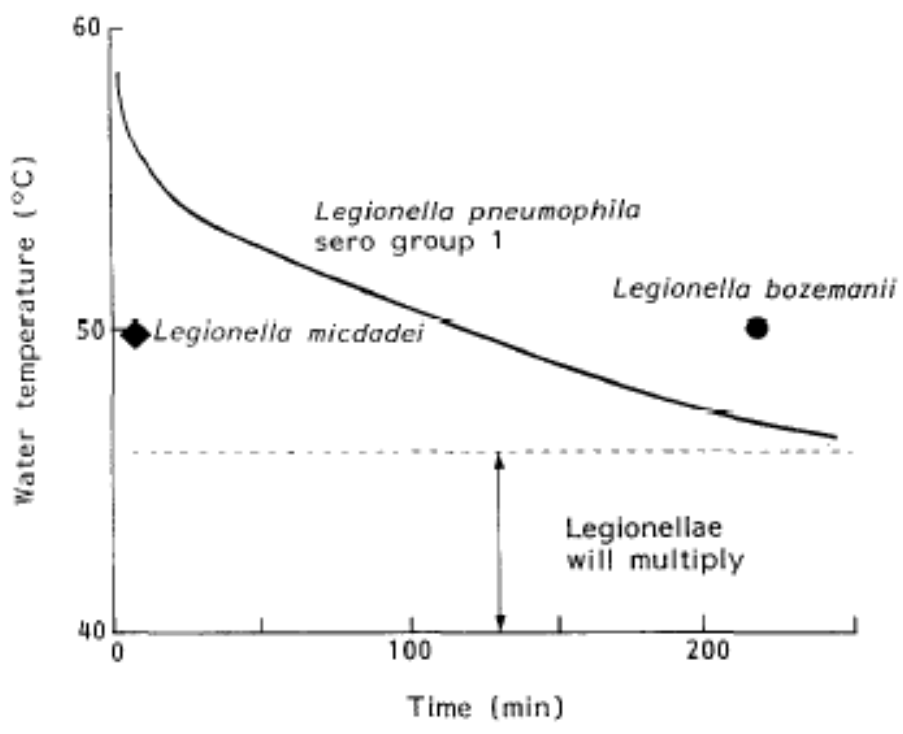

Fig. 2. Time needed to kill 90 percent of the legionella [12]

Therefore, it is essential to install a valve to act as mixer of two different temperatures of water to produce a new desired temperature of water. Recently, Rosli et al., [2] used F-Chart Method to design the domestic water heating system. 


\subsection{Hot Water System Control}

At present, there are several different types of commercial controllers already available in the markets, which are mainly based on microcontrollers, PLC (Programmable Logic Controller, and PID (Proportional Integral Derivative) controllers [13]. These controllers are mainly used for detecting water temperature and level and are responsible for the flow of water [13].

Microcontroller is an embedded controller, which consists of one or more processor cores, memory and programmable input/output peripherals on a single integrated chip. They are designed to perform one specific program and assigned just for one single task at a time. It is cheap and widely available in the market.

Programmable Logic Controller (PLC) is a control system that monitors all the varying inputs and gives out the instructions or decisions based on the custom program to control the outputs. Usually, PLCs are used for industrial systems purposes. It requires a high cost of money to install and configure a single PLC system.

Looking back at the microcontroller and PLC, they are great options if we use them with their right correspondent purposes. But, this new system that requires efficiently performing multiple tasks at a time, a need of cheap cost controller that target the domestic end user, the consumer who usually does not have enough technical knowledge to configure a complex system, a quick data acquisition system that helps in controlling the system make the choice of using the microcontroller and PLC as controller for this new system not reliable enough and unreasonable.

Therefore, in order to meet all the requirements for this new system, a different controller needs to be chosen. Hence, after a thorough analysis, it is decided that this new system will use Raspberry $\mathrm{Pi}$ as the controller. Raspberry $\mathrm{Pi}$ is a low cost and tiny computer that also provides a set of general-purpose input output (GPIO) which allows controlling and monitoring the input and output electronic devices. It also comes in handy for Internet of Things (IoT) purposes. They can operate many tasks at a time and faster processing time compared to microcontrollers. The designing, implementation and configuration of this Raspberry Pi controller will be precisely explained throughout this paper.

\section{Experimental Setup and Methods}

This chapter will explain the concept and development of heat energy supply for the new system, consumer laboratory simulation.

\subsection{Extension of Hydraulic Piping Plan}

This project is aimed to develop an extended version of the existing laboratory set up. The extension is planned for the addition of a system that can efficiently deliver the hot water stored in the storage tank to consumer with some required features. These features include mixing temperature for hot water circulation and delivery, controllable water mass flow rate, remote monitoring and controlling of the system with Raspberry Pi. Figure 3 displays hydraulic piping plan for the extension of the existing laboratory set up. 


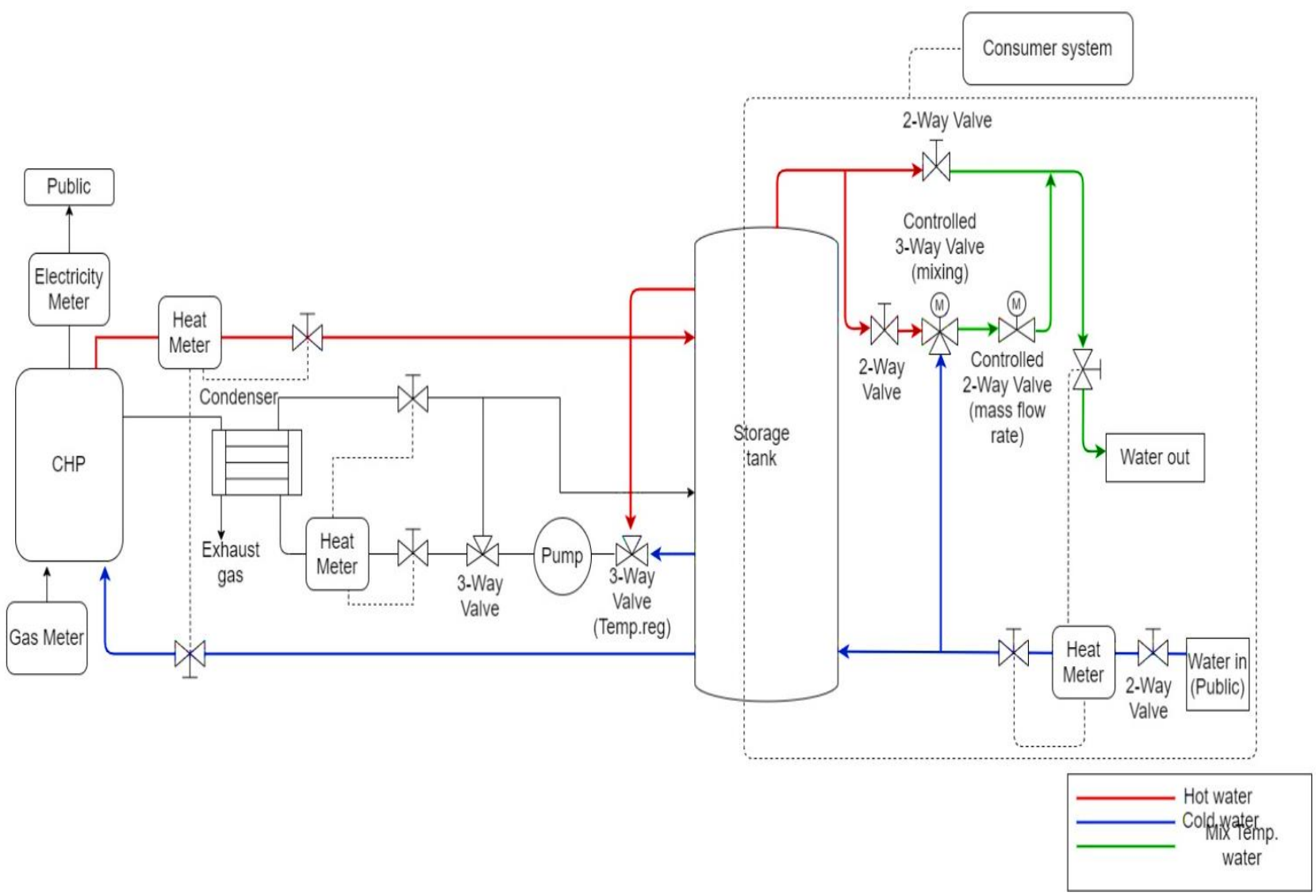

Fig. 3. Proposed version of hydraulic piping plan

Comparing Figure 3 above with the previous piping plan in Figure 1, two piping lines into the existing pipe system after the storage tank are added. One of the lines is a bypass line consisting of three valves; a mechanically operated on-and-off two-way valve and two electrically operated valves (a thermostatic three-way mixing valve and a thermostatic two-way valve). This bypass line is necessary to not disturb the existing pipe system. On the other hand, another pipeline connects the cold-water resource from public distribution pipeline to the one of the thermostatic three-way mixing valve's inlets. The three-way valve is used for mixing two different temperature of water together from two different inlet to get a new temperature of water through one outlet port. While the thermostatic two-way valve is used for proportionally controlling the mass flow rate of water and the mechanically operated on-and-off two-way valve functions as a separator between the bypass line and the existing pipe system. Apart from that, heat meter also is included in the system to measure the temperature at cold-water pipeline from public distribution line and at mix temperature of water pipeline.

\subsection{Mechanical Setup}

A set of structures for piping and several distinguished valves are constructed and assembled to build the extension system mechanical setup. The construction of the extension system is planned to fit within the space, refer to Figure 4. Next Figure 5 shows the installation of pipeline. One pipeline is specified for the extension system and another one is for the existing system. A threeway thermostatic valve is equipped for mixing process of the hot-water source and cold-water source while a two-way thermostatic valve is for water mass flow rate regulator. Other two-way ball valves to block and unblock the bypass pipeline and the extension pipeline. 


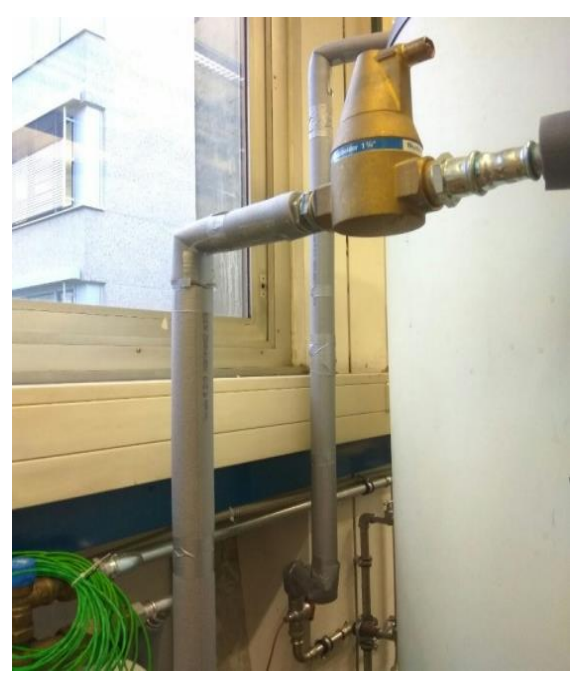

Fig. 4. Extension hydraulic setup area

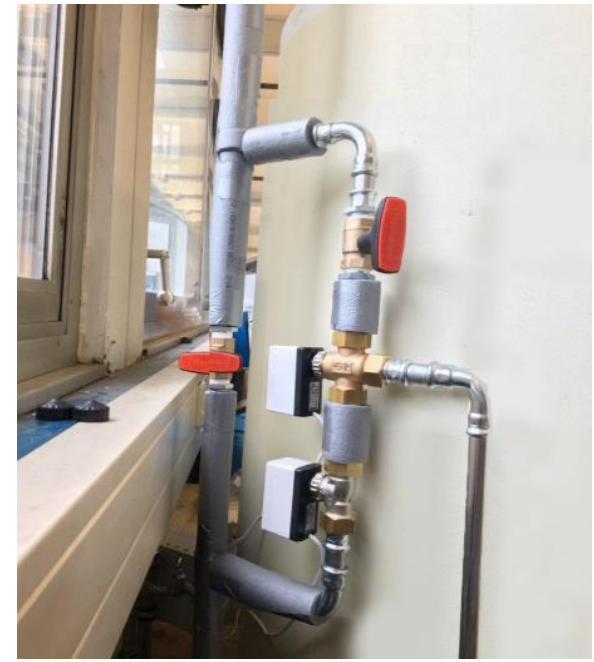

Fig. 5. Mechanical hydraulic setup

\subsection{Controller System}

Our system consists of a Raspberry Pi for system controlling, two PWM to 0-10V converter boards function as PWM signal converter generated by Raspberry Pi to 0-10V signal, two valve actuators; one for controlling the three way mixing valve and another one for two way valve, and a heat meter as data acquisition measuring device. The system uses control loop feedback mechanism where this system will continuously regulate temperature and mass flow rate of the flowed water in the pipeline for the consumer simulation based on the calculated difference of the actual supplied values and the set values. The wiring diagram in Figure 6 displays the wiring connection from power supply connected to the controller, Raspberry Pi to the PWM to 0-10V converter board and finally to the two proportional actuators.

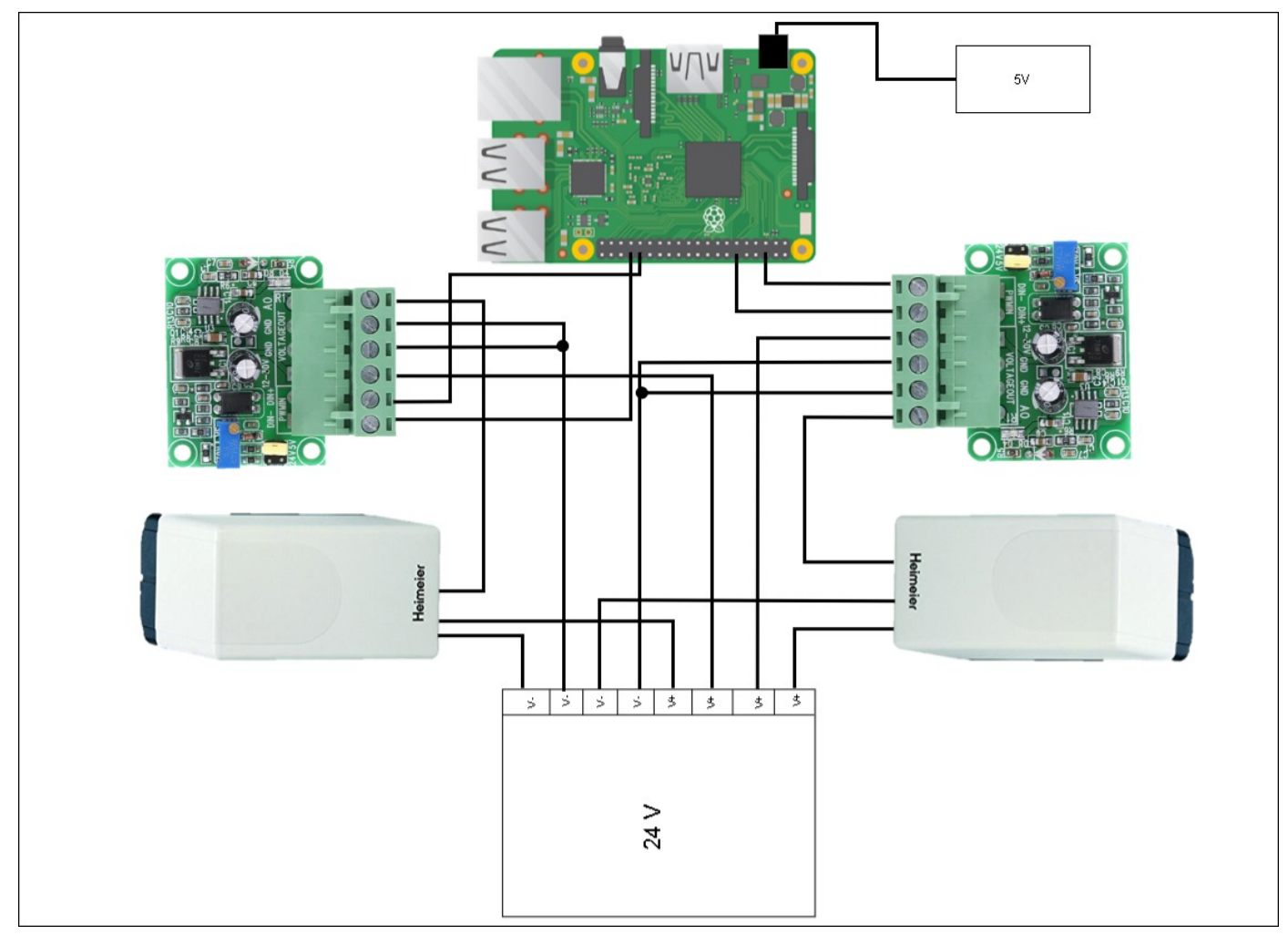

Fig. 6. Consumer system wiring diagram 
Raspberry Pi will act as a controller in this system. The Figure 7 shows the flowchart of the system. The first thing to do before starting the system, we have to initialize the PiGPIO library to the raspberry pi with the command of 'sudo pigpiod'. As the system starts to run, it will first read the set values of thermal power from an excel file. This value will be updated every 1 hour as the system will read a new line of row from the excel file and set it as new set value. Then, it continues to read set point value of temperature that is already defined in the system. The heat meter will act as sensor where it will measure the required actual data (temperature and thermal power supplied) from the running water in the pipeline and send the data to the raspberry pi.

With Proportional-Integral-Derivative (PID) controller implemented in this system, it will calculate the error between the actual values read by heat meter and set values of thermal power and temperature in the running system. Based on the calculated error, the system will generate certain duty cycle value of pulse width modulation (PWM) signal that is needed for the system to maintain the set value. The PWM signal generated by the raspberry pi will then converted to signal in range of $0-10 \mathrm{~V}$ by a converter board. $0 \%$ duty cycle of PWM signal equivalent to $0 \mathrm{~V}$ signal and $100 \%$ duty cycle of PWM signal equivalent to $10 \mathrm{~V}$ signal. The converted signal will then send to the actuators. OV signal will fully close the valve and $10 \mathrm{~V}$ signal will fully open the valve. The raspberry pi also serves a saving data feature from the running system for the management of temperature load profile. This means, all data that are needed to construct a temperature load profile are saved along the running system.

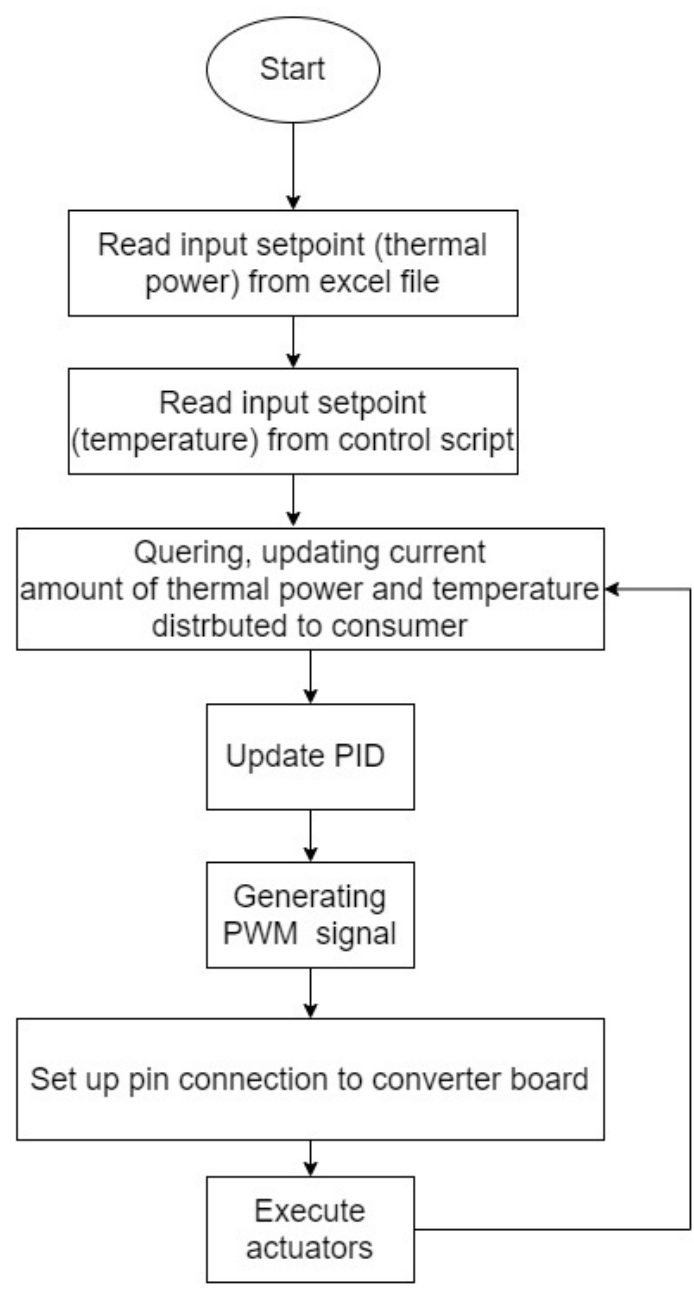

Fig. 7. Consumer system flow chart 


\section{Results and Discussion}

From the system establish, users can easily plan the thermal energy usage. In order to validate this new developed system, a test is conducted by running the system continuously for several hours. A set temperature of $15^{\circ} \mathrm{C}$ and the amount of thermal power for every 1 hour is increased by just $100 \mathrm{~W}$ are set to operate the system.

Figure 8 shows a graph of thermal power over time. X-axis is for thermal power (W) with interval of $100 \mathrm{~W}$ and $\mathrm{Y}$-axis is for time (h) with interval of $1 \mathrm{~h}$. The blue line represents the set thermal power while the orange line represents current/ actual thermal power.

In the graph (Figure 8), it is shown that the set thermal power is increased by $100 \mathrm{~W}$ every 1 hour. This means that the system needs to control the actual output thermal power to be at $100 \mathrm{~W}$ for the first one hour and increased by another $100 \mathrm{~W}$ after one hour.

Based on the graph (Figure 8), it is calculated that the accuracy of the system to maintain the set thermal power is $+/-0.3 \mathrm{~kW}$.

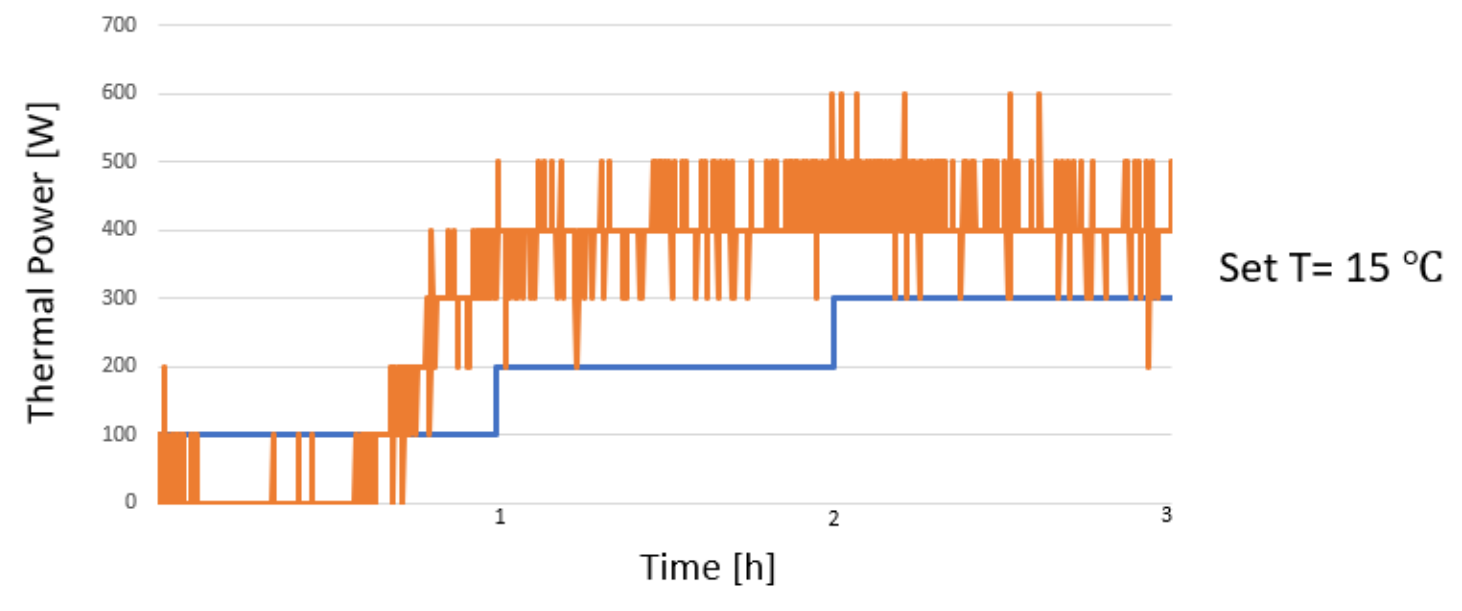

Set Thermal Power $\quad$ Current Thermal Power

Fig. 8. Thermal power versus Time

Figure 9 shows a graph of temperature over time. X-axis is for temperature $\left({ }^{\circ} \mathrm{C}\right)$ with interval of $2^{\circ} \mathrm{C}$ and $\mathrm{Y}$-axis is for time (h) with interval of $1 \mathrm{~h}$. The graph is separated into three segments, which are $100 \mathrm{~W}, 200 \mathrm{~W}$ and $300 \mathrm{~W}$ this means that for the first hour, the system is set to run to achieve $100 \mathrm{~W}$ thermal power output and then it will increase by another $100 \mathrm{~W}$ every one hour. The blue line represents the current/ actual temperature while the orange line represents set temperature.

The system needs to maintain the set temperature of $15^{\circ} \mathrm{C}$ throughout the three hours. Based on the graph (Figure 9), it is calculated that the accuracy of the system to maintain the set temperature is $+/-1^{\circ} \mathrm{C}$.

The graph shows that the result from the measurement of a running system is not so good. This is because the possibility for the system to accurately function is low as the difference of temperature is too low and the set thermal power is too small. We believe if the temperature difference is high and the set thermal power is big, the function of the system in maintaining the set point values can be realized. 


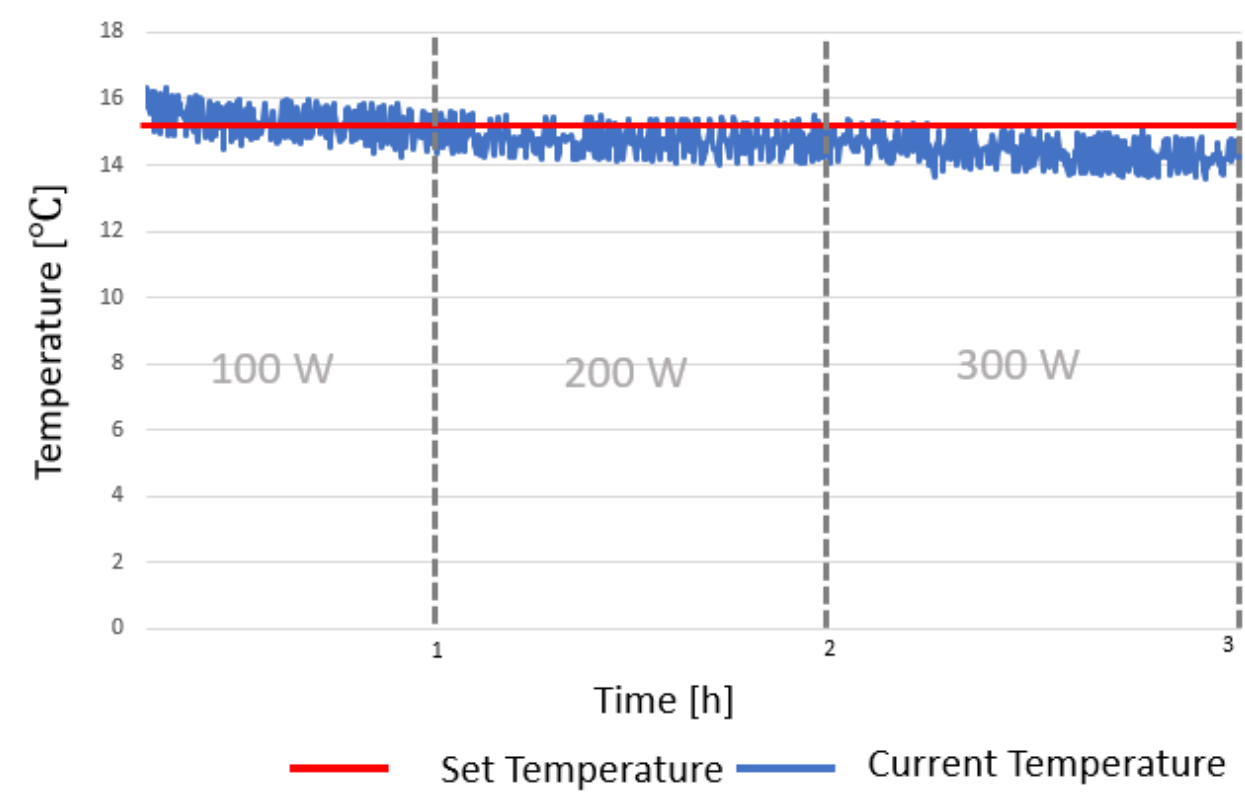

Set $\mathrm{T}=15^{\circ} \mathrm{C}$

Fig. 9. Temperature over Time

\section{Conclusions}

In conclusion, a system that provides a flexible controlling mechanism to the amount of heat energy distributed to the consumer was successfully created. Any sudden changes to the set input variables and all the controlled output parameters in this system are monitored and the system will act accordingly to achieve the desired output.

As shown in the result section, this new developed system delivers the desired operating values down to accuracy of $+/-1^{\circ} \mathrm{C}$ for temperature value and $+/-0.3 \mathrm{~kW}$ for thermal power value. With these values of accuracy, the system can manage the heat energy distributed to the consumer at an optimum level.

In addition, there is also an established connection to the energy manager for sending and receiving data. This connection is very important to allow monitoring and data analysis in order to validate and verify an effective system in the long run time. Besides, this system is very economic for the consumers. All the mechanicals, electrical and software setups for the system are affordable. They also have high quality and complies with the industry standard. In the long term, this system is very significant to conserve energy, resources and save cost. For future implementation, this system is ready to be integrated to any new upgrades. With these properties, a high-level efficiency of the system can be achieved.

\section{Acknowledgement}

The authors would like to acknowledge the financial support from Universiti Malaysia Pahang and Hochschule Karlsruhe-Technik und Wirtschaft (HsKA) under grant number RDU192703 and UIC191514.

\section{References}

[1] Nallagownden, P., T. H. Bao Huy, R. Kannan and V. N. Dieu. "Energetic Optimization of Solar Water Heating System with Flat Plate Collector using Search Group Algorithm." Journal of Advanced Research in Fluid Mechanics and Thermal Sciences 61, no. 2 (2020): 306-322.

[2] Rosli, M. A. M., D. S. M. Zaki, F. A. Rahman, S. Sepeai, N. A. Hamid and M. Z. Nawam. "F-Chart Method for Design Domestic Hot Water Heating System in Ayer Keroh Melaka." Journal of Advanced Research in Fluid Mechanics and Thermal Sciences 56, no. 1 (2019): 59-67. 
[3] Kuansin, M.E. "Measurement Recording and Evaluation of Data and Characteristic Values for the Analysis of Performance and Efficiency of a Combined Heat and Power Unit." Hochschule Karlsruhe Technik und Wirtschaft: Forschung aktuell (2019).

[4] Rettenmeier, P. "Entwicklung einer graphischen Füllstandsanzeige für einen Wärmespeicher." Hochschule Karlsruhe Technik und Wirtschaft: Forschung aktuell (2019).

[5] Chow, H. K., N. A. C. Sidik, S. N. A. Yusof, M. Beriache and A. T. Mohamad. "Performance Enhancement of Cold Thermal Energy Storage System using Nanofluid Phase Change Materials." Journal of Advanced Research in Applied Mechanics 62, no. 1 (2019): 16-32.

[6] SenerTec. "Dachs G/F Gen2 - Technical Data." (2020). Retrieved from https://senertec.com/wpcontent/uploads/2018/12/Technical-Data-Dachs-Gen2.pdf.

[7] Buderus. "Technical description of system components." In Technical guide - Logasol solar technology for domestic hot water heating and central heating backup, pp 25, 2007.

[8] Bhatia, A. Design Consideration for Hot Water Plumbing. New York: Continuing Education and Development, Inc.

[9] Centers for Disease Control and Prevention. "Legionella (Legionnaires' disease and pontiac fever)." $A-Z$ Index. Available online: http://www. cdc. gov/legionella/about/diagnosis. html (accessed on 6 December 2016) (2018).

[10] Stephen, F. R., and J. P. Murray. "Prevention of hot tap water burns-a comparative study of three types of automatic mixing valve." Burns 19, no. 1 (1993): 56-62.

https://doi.org/10.1016/0305-4179(93)90102-E

[11] Zikri, A., E. A. Kosasih, M. I. Dzaky and Firdaus. "Combination of Dehumidifier, Heat Pump and Air Heater: Influence of Temperature, Specific Humidity, And Mass Flow Rate of Air on Specific Energy Consumption." Journal of Advanced Research in Fluid Mechanics and Thermal Sciences 76, no. 1 (2020): 124-134. https://doi.org/10.37934/arfmts.76.1.124134

[12] Dennis, P. J., D. Green, and B. P. C. Jones. "A note on the temperature tolerance of Legionella." Journal of Applied Bacteriology 56, no. 2 (1984): 349-350. https://doi.org/10.1111/i.1365-2672.1984.tb01359.x

[13] Hasan, M. R., K. Arifin, A. Rahman, and A. Azad. "Design, implementation and performance of a controller for uninterruptible solar hot water system." In 2011 IEEE 18th International Conference on Industrial Engineering and Engineering Management, pp. 584-588. IEEE, 2011.

https://doi.org/10.1109/ICIEEM.2011.6035226 